\title{
Mitos fronteiriços como resgate memorialístico
}

\author{
Mitos fronterizos como rescate memorialístico
}

\author{
Bordermyths as a memory rescue
}

Ma. Ariane Borba Clos ${ }^{1}$

\begin{abstract}
Resumo
Acredita-se s que pela análise mítica seja possível resgatar a memória e a identidade de determinada região. Na fronteira do sul do Brasil com o Uruguai, nas cidades Jaguarão e Rio Branco, as narrativas de teor mítico parecem permear o imaginário dos habitantes e fazer parte da identidade local. Uma primeira alusão a esses mitos está no nome Jaguarão, oriundo do mito do Jaguar, que pode ser considerado um mito primordial, visto que conta a origem de uma cidade. No contato com a produção musical desenvolvida na referida fronteira percebe-se a influência de narrativas míticas, transmitidas pela oralidade por narradores sociais como pescadores, benzedeiras, peões de estâncias, avós, pais, etc. A partir da análise de algumas músicas pretende-se apresentar alguns mitos regionais mostrando como o estudo de mitos pode contribuir para um resgate memorialístico e da identidade fronteiriça.
\end{abstract}

Palavras-Chave: mito, fronteira, memória

\section{Resumen}

Se cree que por el análisis mítico es posible rescatar la memoria y la identidad de determinada región. En la frontera del sur de Brasil con Uruguay, en las ciudades Yaguarón y Rio Branco, las narrativas míticas parecen permear el imaginario de los habitantes y hacer parte de la identidad local. Una primera alusión e esos mitos está en el nombre Yaguarón, que viene del mito del yaguar, y que puede ser considerado un mito primordial ya que cuenta el origen de una ciudad. En el contacto con la producción musical desarrollada en la referida frontera se percibe el influjo de narrativas míticas, transmitidas por la oralidad por narradores sociales como pescadores, brujas, peones de haciendas, abuelos, padres, etc. Desde el análisis de algunas músicas vamos a presentar algunos mitos regionales mostrando como el estudio de mitos puede contribuir para un rescate memorialístico y de la identidad fronteriza.

Palabras claves: mito, frontera, memoria

\begin{abstract}
We believe that you can redeem a memory and the identity of a region by a mythical analysis. The mythical content of narratives seem to permeate the minds of the people and part of the local identity on the border of Brazilian South and Uruguay, at Jaguarão and Rio Branco cities. One of the first mention of these myths is in the name of Jaguarão city, derived of Jaguar myth, which can be considered a major myth because it tells the origin of a city. We see the influence of mythical narratives in the contact of the musical production developed on this border. They are transmitted by oral tradition by social narrators such as fishmen, witch doctors, ranch workers, grandmothers, parents, etc. From the analysis of some musics we intend to present some region myths showing how the study of myths can contribute to a memorialistic rescue and a border identity.
\end{abstract}

\footnotetext{
${ }^{1}$ Mestra em Linguística e Letras; Universidade Federal de Pelotas - UFPel, Pelotas, Rio Grande do Sul, Brasil. arianebclos@gmail.com
} 
Keywords: myth, border, memory

\section{A perspectiva mítica}

Definir o que é mito é tão complexo quanto compreendê-lo. São muitas as abordagens possíveis, entretanto, a perspectiva deste trabalho tem por base as concepções de Campbell(1990) e Eliade (1968). A partir desse embasamento, entendemos que por meio da interpretação de símbolos e de sua leitura conotativa seja possível chegar ao mistério do mito.

\subsection{0 mito como caminho}

Para Campbell (1990) os mitos são metáforas da realidade. Analisá-los dessa maneira é compreender que por eles nos aproximamos de uma harmonia universal, partindo de nossa essência humana, pois olhar para um mito é como olhar para um espelho. É a ideia de um encontro com a natureza primitiva que habita em cada um de nós.

Se algo nos emociona, e aqui incluímos a música e outras manifestações artísticas e culturais, é porque tocou o profundo de nosso ser, a nossa essência, que aqui chamaremos de identidade. Salientamos que a concepção de identidade, apresentada neste trabalho, surge da correlação dos estudos de Hall(2003) sobre identidade e de Cambpell(1990) sobre mito. Além dessas abordagens, nos valemos dos estudos de Eliade (1968). Este autor defende que os mitos se referem à espiritualidade, de alguma maneira, pois em cada indivíduo existe uma consciência ancestral. Por isso é natural buscar em religiões, crenças e rituais essa memória que se encontra em cada um, embora esteja inconsciente. Cambpell diz que a grande descoberta mítica é o encontro do eu interior com o eu universal. Pelos ritos é possível preservar narrativas míticas e estabelecer a conexão entre o plano terreno e o plano espiritual, entre o momento presente e um passado ancestral e inconsciente. Para Zanotelli, "a parábola, o mito, a poesia [...] é o único modo de aceder à verdade das coisas, do mundo e de Deus." (ZANOTELLI, 2007, p.33).

Campbell e Eliade estão de acordo que a grande lição do mito é revelar o caminho para se chegar a nossa essência, que se manifesta além do corpo e em sintonia com o universo. Entendendo os mitos, entende-se que a eternidade não é uma questão de tempo, mas de condição. Entender que essa conexão com o universo acontece de forma espiritual, portanto eterna, é entender o que é mito. O mito não é somente um conceito ou gênero literário, ele se refere a energias que reverberam desde que o mundo é mundo. A própria 
criação do mundo é um mito o que nos leva a crer que talvez os mitos existam antes mesmo da humanidade.

O homem cria narrativas míticas para compreender o que a razão e a ciência não conseguem explicar. Para estudá-las é preciso antes compreender que os mitos têm dimensões que fogem do alcance dos nossos olhos humanos, que se referem a realidades que estão além da temporalidade, mas que são narrativas que podem auxiliar a compreender a sociedade da qual fazemos parte. Os mitos também contam a história da humanidade desde os tempos mais remotos e, a partir de sua análise, podemos compreender as crenças, os costumes e as identidades de quem os criou.

Seguindo essa linha, Hall (2003, p.50) diz que o mito fundacional serve como exemplo de narrativa de cultura nacional, ou seja, dessas representações simbólicas que auxiliam na percepção de nosso entorno e, consequentemente, de nós mesmos. O autor menciona os princípios espirituais que dão unidade a uma nação, apontados por Ernest Renan. São eles: uma memória coletiva, a vontade de viver em conjunto e a de perpetuar a herança recebida. Segundo Hall esses três aspectos contribuem para a formação da cultura como uma comunidade imaginada ${ }^{2}$ e questiona se uma identidade nacional não acaba unificando culturalmente os diferentes gêneros sociais a ponto de homogeneizar a própria cultura. (HALL, 2003, p.58-59).

Homogeneidade essa utópica, pois não se pode falar de identidade nacional nem definir identidade como um conceito diferente de heterogêneo. Da mesma forma a região de fronteira pode ser vista como heterogênea e como espaço simbólico, por inspirar a criação de mitos que contribuem para formação da identidade do fronteiriço. Evidentemente nem todas as fronteiras têm essa característica, mas em Jaguarão elementos simbólicos são chamativos até para o turista mais distraído.

O estudo dos mitos desperta a percepção sobre os símbolos que estão em nosso entorno. A simbologia faz parte de nossa vida diária e pode ser interpretada, se formos capazes de percebê-la. No livro o Homem e seus símbolos, Jung (2008) discorre sobre o poder simbólico dos sonhos na compreensão de nosso inconsciente. Relacionando esse estudo com o estudo de Campbell sobre os arquétipos míticos entendemos que ao tentarmos decifrar o significado de um sonho, estamos olhando para o nosso inconsciente e quando percebemos alguma forma de simbologia no mundo terreno estamos tentando entender o inconsciente

\footnotetext{
2 O conceito de comunidade imaginada, proposto por Benedict Anderson, pode ser aprofundado em ANDERSON, Benedict. Comunidades Imaginadas. São Paulo: Companhia das Letras, 2008.
} 
coletivo. Para Jung (2008), nas tribos primitivas o homem tinha duas consciências, e uma delas se relacionava a uma alma do mato, onde os homens se identificavam com alguma árvore ou animal.

Essa consciência ancestral se reflete em nossos dias, mas de forma inconsciente. Ela pode estar representada em símbolos culturais como a ponte binacional Barão de Mauá, os casarões tombados, as ruas ainda de calçamento emolduram uma paisagem quase anacrônica. Essa concepção de fronteira como um lugar de cultura plural e simbólica será abordado no capítulo a seguir.

\section{A fronteira como lugar de integração cultural}

A fronteira que delimita a cidade brasileira Jaguarão com sua vizinha uruguaia Rio Branco é um lugar de cultura plural. A distância que separa as cidades fronteiriças das capitais de seus respectivos países pode contribuir a formação de uma cultura local compartilhada. Tão complexo quanto definir mito, é definir fronteira. Esse conceito pode ser analisado por diferentes perspectivas: política, cultural, geográfica. Para uma delimitação teórica de fronteira é preciso, primeiramente, situá-la no espaço e no tempo.

Consideramos que, culturalmente, entre dois países, se as fronteiras geográficas os aproximam e se as relações políticas são amigáveis, os limites culturais se expandem, nos levando a compreender a fronteira com um lugar cultura plural.

\subsection{De(limitando) a fronteira}

No decurso da história vemos que as delimitações territoriais foram estabelecidas muitas vezes de forma conflituosa. Em alguns casos a topografia de um rio ou de uma cordilheira contribuiu para as demarcações, porém 'as fronteiras cortaram ao meio um mesmo espaço étnico, dividindo uma mesma cultura, separada em países diferentes. Este fato é mais comum do que se imagina, e ocorre principalmente quando as fronteiras são delimitadas por rios, florestas, montanhas, ou desertos'. (DIAS, 2011, p.4).

Isso faz com que apesar de encontros culturais, haja, inevitavelmente, uma ruptura também nas relações históricas, nos tratados políticos; o que para os povos fronteiriços faz pouco ou nenhum sentido, já que as relações culturais e afetivas imperam.

Essa discussão é necessária, porque a fronteira da qual estamos falando é um lugar único que congrega a cultura de ambos os países e as manifestações culturais dessa região denotam uma singularidade tipicamente fronteiriça, que pode ser entendida como identidade local. 
Não há como separar uma cultura que na mistura se faz una. Associando com os conjuntos numéricos, resgatando nossa memória escolar, temos uma imagem que pode facilitar a compreensão do que é a identidade e a memória desse lugar. Imaginemos a intersecção de dois países, onde um está contido no outro. Nesse conjunto há regiões que são independentes a cada país, mas há um ponto de encontro, que é na verdade uma fusão de dois espaços, um lugar como a comarca pampeana concebida por Ángel Rama, porém em menor proporção. Nesse espaço comum, denominado fronteira, acreditamos encontrar a memória e a identidade do fronteiriço.

Essa identidade compartilhada pode ser percebida no cotidiano dos fronteiriços quando "vecinos de Yaguarón expresen que 'lo más lindo de Yaguarón es el balneario Lago Merín' y que coincidiendo con vecinos de Rio Branco declaren que 'el rio nos une y el puente nos separa"”. (MAZZEI,2013, p. 77).

Essa citação demonstra como a vida no entorno do rio Jaguarão é partilhada em suas relações comerciais, familiares, empregatícias, de moradia, etc. É um espaço único, separado por um rio e pelo idioma, mas unido por uma ponte e pelas relações afetiva, dialetal e cultural. Dentro disso, estamos de acordo que fronteira(s) são:

marcos simbólicos, locus privilegiado de encontro com a diversidade e, talvez por isso mesmo, espaços de tensão, simbólica e real. A construção das fronteiras pode ser verificada no interior da cultura, a exemplo do "imaginário" e do "maravilhoso". O imaginário é um dos fenômenos culturais que englobam as formas de pensar, as cosmologias e cosmogonias, ou seja, as representações que o homem cria sobre o seu universo simbólico. (DIAS,2011, p.8).

A partir desses estudos, acreditamos que os mitos da fronteira são formadores da identidade do fronteiriço e contribuem para o resgate da memória dessa região. O espaço de fronteira se consolida de maneira híbrida, moldado por características de dois países distintos, línguas diferentes, mas histórias comuns que estimulam a criação de narrativas míticas. Saber que logo ali tem um outro, que é diferente de mim, seja pela língua ou pela nacionalidade, reforça a minha identidade e tem uma aura de magia. É a sensação dúbia de estar em casa, mas em outro país.

Em contato com o outro eu me defino; na dialogia eu descubro quem sou. Olhando para o outro eu olho para mim e conheço a minha essência. O mito parece um bom caminho para esse encontro. Da mesma forma, ao observar uma narrativa mítica, se observa, também a comunidade que a criou, e a identidade de determinada região. Assim, na música abaixo, é mais fácil compreender o exposto; nossa afirmação ganha evidência: 


\author{
Jaguar Grande do Sul \\ Letra: Martim César e Alessandro Gonçalves \\ Música: Paulo Timm e Régis Bardini \\ Um grito e o silêncio na beira do rio \\ Mais um que se foi... pra sempre sumiu \\ Uns contam que ouviram de quem nunca viu \\ Do medo que assombra por anos a fio \\ Foi lá no tempo dos índios charruas \\ Tudo era verde nas terras do sul \\ Matas, aguadas, o sol e a lua \\ Não sabiam do ouro, das leis ou da cruz. \\ Chegaram os brancos trazendo a fronteira \\ Os mapas, as guerras, o luzir dos metais \\ Se foi o sonho da mesma bandeira \\ Restou a história que contam meus pais: \\ Vidas e mortes, sonhos e medos \\ Tantos segredos pelo rio do lugar \\ Grito e silêncio na noite escura \\ Tem gente que jura que é o Jaguar. \\ Talvez a mandinga de um pajé feiticeiro \\ Por vingar uma raça arrancada da terra \\ Fez nascer pelas margens desse rio povoeiro \\ Um ser que era mescla de peixe e de fera. \\ Talvez... pois ao certo não se soube jamais \\ Quem chegou muito perto não viveu pra contar \\ Ao abrir-se a barranca...era tarde demais \\ Pra se crer na história desse estranho Jaguar.
}

Nessa música, de compositores fronteiriços, há vários elementos de cunho mítico, histórico, identitário e memorialístico. A música trata de um mito de origem ou um mito cosmogônico. O termo cosmologia, assim como a mitologia, apresenta o radical grego logos, que como sabemos significa o estudo sobre algo, no caso a cosmogonia. Esta por sua vez é a visão de cada cultura sobre a origem do cosmos, do mundo. O mito do jaguar não trata da origem do mundo de forma ampla, mas da origem de um mundo particular: Jaguarão, a cidade e o rio.

Os mitos servem como resgate memorialístico, porque diferentemente das fábulas ou das lendas eles se referem a realidades, como diz Eliade. O mito do jaguar se baseia na existência desses felinos que habitavam as margens do rio, e que povoam o imaginário de diversos países da América Latina, dados que depreendemos dos registros da história e da biologia. 
Voltando-nos para o nosso objeto de análise, vemos que na música citada há uma menção ao tempo dos índios charruas, à chegada dos espanhóis e dos seus jesuítas catequizadores. As disputas territoriais também são pontuadas, mas por fim "restou a história que contam meus pais", que podemos entender como os mitos são transmitidos oralmente pelos antepassados até os dias atuais.

Os mitos se valem de fatos que instigam o imaginário e vão tomando forma, se modificando ao longo do tempo, se adaptando às culturas nas quais se inserem. Felinos como o jaguar inspiram narrativas por toda a América. A título de exemplo e partindo do particular para o universal podemos citar "As grandes onças brabas", de Aldyr Schlee; "Meu tio Iauaterê", de João Guimarães Rosa; El oro pelado y otros cuentos de la selva, de Horácio Quiroga, Leyendas de Guatemala, de Miguel Ángel Astúrias. Nas obras desses escritores encontramos felinos como o jaguar, fazendo vezes de personagens.

A literatura e o mito têm a particularidade de contribuir para a história, ao passo que dela também dependem. A partir do conceito aristotélico de mímesis, entendemos que o texto literário está composto, em alguns casos, por situações acontecidas ou passíveis de ter acontecido. Assim, compreendemos que não se trata de uma mera criação, mas surge a partir de fatos, assim como os mitos. Desse modo, auxilia na formação da cidadania e de identidades. No entanto, os mitos vão além; levam-nos para outras dimensões, resgatam memórias escusas que estão no inconsciente coletivo. Rastreando os mitos podemos chegar em fatos e reescrever a História. Pois um mito necessariamente nasce de um fato.

Na música "Rio Jaguarão", o mito do jaguar está implícito, mito que inexiste sem o rio. O rio é ambiguamente marcante na vida do fronteiriço e parece ser um símbolo importante, já que suas águas unem o Brasil ao Uruguai e ao mesmo tempo separam. O rio integra o território de ambos os países, mas parece ter uma relação mais forte com os jaguarenses, cuja a geografia da sua cidade apresenta a construção das casas, a disposição das ruas a se organizarem a partir do rio, estabelecendo a relação de proximidade que aqui afirmamos, ademais, constituindo uma marca identitária. Assim, o imaginário local se relaciona diretamente com o rio e com o mito do jaguar, e estimula criações artísticas como a que segue.

\section{Rio Jaguarão (Paulo Ricardo Oliveira e Edgar Martins)}

Diz que quem bebe em tuas fontes

E prova o doce amargo do amanhã

Encanta-se com o rio nas taipas do entardecer 
RELACult - Revista Latino-Americana de Estudos em Cultura e Sociedade

Revista Latinoamericana de Estudios en Cultura y Sociedad | Latin American Journal of Studies in Culture and Society

V. 02, Ed. Especial, dezembro, 2016, p. 864-873 | periodicos.claec.org e-ISSN 2016/Atual: 2525-7870 | e-ISSN 2015/2016: 2447-018X

Ronda a noite a estrela guia o amanhecer

E lava o rosto em suas margens

Carrega de sonhos nas mãos

Navega nas ondas minha alma

Rumo à lagoa o Jaguarão

Rio rasgando a fronteira

Beijando barrancas hermanas brasileiras

Águas que brotam além mar

Rio mesclando a fronteira

A ponte Mauá em tuas águas se espelha

Unindo o Brasil e o Uruguai

No alto do cerro da pólvora

De ronda a enfermaria sempre está

Mirando desde lejos horizontes

O céu azul a pampa amada e o rio a passar

Rio de contos e lendas

Correntezas, banhados e aceguás

Galopa em silêncio tuas águas

$\mathrm{O}$ canto da terra com o rio que se vai

Outra composição musical importante para se compreender os mitos fronteiriços tratase de Velho Chico brasileiro, de autoria de Hélio Ramirez:

\section{Velho Chico brasileiro (Hélio Ramírez)}

Triste fim de uma jornada

Triste fim de uma estrada

Pra quem é tão brasileiro

Choram desde a Serra da Canastra

Paulo Afonso, Sobradinho

Juazeiro, Praia do Peba.

Deem ouvidos aos barqueiros

Pescadores, carranqueiros, Lavadeiras, ribeirinhos

Estes sim, conhecem o Chico

Com a alma despojada

Dos que vivem a natureza

Cada porto, cada curva

$\mathrm{O}$ dourado...o surubim

O cantar do acauã

Num remanso em Pirapora

Quem tem nome de Francisco

Santo é...santo é...

Inda mais se for um rio

Onde as garças voam lentas

Tendo o poente majestoso

Sobre as flôdos aguapé" 
Nessa música não temos uma narrativa mítica, o compositor não se vale do imaginário indígena das lendas que narram poeticamente o nascimento do rio, o mito de origem e seus protagonistas indígenas. No entanto, para render a sua homenagem ao importante rio, observa a geografia, como a nascente situada no estado de Minas Gerais, mais precisamente na Serra da Canastra e o seu curso que perpassa diversos estados do Nordeste. Além disso, nomeia os grupos sociais que interagem e obtêm o sustento das águas do rio, destacando os seus saberes de sujeitos populares. Esses são os sujeitos que se conectam com os mitos e que estabelecem a conexão do individual com o universal. Em conformidade com essa visão, a música "Barqueiro Rio Jaguarão", de autoria do mesmo compositor, expressa nos versos "anda rápido, anda ligeiro/ que a noite vem aí/ cuidado com o jaguar grande/ te espreitando nos sarandi" a presença do mítico no cotidiano do trabalhador comum, o barqueiro, aquele que entende e compartilha da linguagem do rio.

Há algo que subjaz à letra e até mesmo à memória. São questões ontológicas e idiossincráticas que fazem com que morador da fronteira sul do Brasil, com o Uruguai vivencie um sentimento parecido daquele dos ribeirinhos do São Francisco. O rio é outro, mas ele também é tido como uma matéria viva e pertencente a uma região.

\section{Considerações finais}

O estudo dos mitos se encaixa como uma abordagem teórica possível na compreensão do imaginário, dos aspectos identitários e memorialísticos de determinadas culturas. Até porque podemos relacionar as criações míticas não só dentro de um mesmo espaço territorial, mas além das fronteiras. Dessa forma, rastreando um mito local chegaremos ao nosso eu mais primitivo e a questões que são inerentes à condição humana, alheias a regiões.

As relações entre razão e emoção nos aproximam enquanto seres humanos. Os mitos, independentemente da cultura tentam explicar o que a razão não atinge, porque há coisas que são inefáveis. E esse é o grande mistério. A grande descoberta mítica é esse encontro do mundo interior, individual com o mundo exterior, universal.

Os mitos nascem em nosso inconsciente e manifestam de forma simbólica e quase imperceptível. Por isso o estudo de mitos enquanto corrente teórica pode contribuir no estudo da história, da memória, da literatura, de saberes que trabalham de alguma maneira com identidade.

Se os mitos são metáforas da realidade, é presumível que se disfarcem de criações artísticas. E por observarmos que músicas com temática mítica parecem comuns na região fronteiriça de Jaguarão, procuramos mostrar de que maneira as teorias sobre mito se 
relacionam com questões ontológicas e, consequentemente, identitárias. Sugerimos que a descoberta mítica contribui para o resgate de nossa memória ancestral inconscientemente esquecida.

\section{Referências}

CAMPBELL, Joseph, O poder do mito, com Bill Moyers; org. por Betty Sue Flowers; tradução de Carlos Felipe Moisés. São Paulo: Palas Athena, 1990

DIAS, Renato. Lugares de fronteira: espaço territorial, simbólico e identitário - um ensaio.In Temporalidades - Revista Discente do Programa do Programa de Pós-graduação em História da UFMG, vol. 3n. 1. , 2011 Disponível em: http://www.fafich.ufmg.br/temporalidades/pdfs/05p275.pdf Acesso em ago de 2016

ELIADE, Mircea. Mito y realidad. Madrid: Guadarrama, 1968.

HALL, Stuart.A identidade cultural na pós-modernidade. Tradução Tadeu da Silva, Guaracira Lopes Louro. Rio de Janeiro: DP\&A, 2003.

JUNG, Carl. O homem e seus símbolos. Rio de Janeiro:Nova Fronteira, 2008.

MAZZEI, Enrique. Fronteras que nos unen y límites que nos separan. Melo: Imprenta CBA, 2013.

RAMIREZ, Helio; TIMM, Paulo; CESAR, Martim. Caminhos de si. O tempo. Direção artística: Paulo Timm. Pelotas: Estudio Levi, 2015. 1 CD (70 min). Disponível em: http://ofiodanavalha.com/playlist/caminhos-de-si-o-tempo/ acesso em set de 2016.

VELLOSO, Monica. História, Literatura e memória: uma discussão sobre universos fronteiriços. Mouseion, n11, jan-abr, 2012, p.4-22, 2012. Disponível em: http://www.revistas.unilasalle.edu.br/index.php/Mouseion/article/view/364 Acesso em ago de 2016.

ZANOTELLI, Jandir. América Latina: raízes sócio-político-culturais. Pelotas: Educat, 1999. 